\title{
Note on drug treatment of complete heart block
}

\author{
H. A. Fleming and Sheila M. Bailey \\ From The Regional Cardiac Unit, Papworth Hospital, Cambridge
}

Eight years of personal experience of long-acting isoprenaline in the treatment of chronic complete heart block is described. In selected patients the long-term results can be very satisfactory and examples are given. The isoprenaline infusion test is invaluable in selecting most patients who

- will not do well on long-acting isoprenaline. Of those who begin on treatment about half have done well. This form of treatment has proved useful before the setting up of a regional pacemaking service and it continues to be suitable in selected cases. It will continue to have an application in areas of the world where efficient pacemaker services cannot be provided.

In 1963 this Unit reported the use of long- acting isoprenaline (Saventrine) in the treatment of complete heart block in 8 patients (Fleming and Mirams, 1963). Two of these had died before the report was published; 4 of the remaining 6 survive and are in good health at the time of writing 8 years later. This is a better result than might have been anticipated with the pacemakers available in 1962-63 in this region. Since then pacemakers and their problems have vastly improved and there is now a tendency to pace most patients with bradycardia. However, our own experience with long-acting isoprenaline has continued to be satisfactory in selected patients, and similar findings have been reported by Bluestone and Harris (1965), El-Nahas and Johnson (1966), and Redwood (1969).

We felt that the time had now come to review briefly our own experience with Saventrine to date.

\section{Subjects}

We first present the 8 cases - the subject of the - original report (Table).

\section{Comment}

In the individual patient the dose has varied from time to time and patients have needed a good deal of attention to detail to establish precisely the regimen which suited them best.

- This is not only essential to establish an adequate therapeutic effect but often to avoid important side effects.

Case I who has been on treatment for nearly 8 years can easily show that his wellbeing is dependent on his present dose. A

Received I June 1971. small reduction will reduce his ventricular rate conspicuously and he will feel less well. He adjusts his own dose to fit in with seasonal variations in his activity.

Of the 4 patients who died, 2 did so in the early stages and one after 2 years of treatment. There were no necropsies in 2 of these cases but it is reasonable to assume that death was due to the heart condition and, in the third, necropsy revealed recent thrombotic occlusion of the right main coronary artery. One patient died from bronchial carcinoma after 3 years of uneventful Saventrine treatment.

There were no important side effects in this group apart from slight diarrhoea at the beginning of treatment in 2 cases. Case 7 was recently found to have a tremor and palpitations in the morning but these were abolished without loss of rate by adjusting the regimen.

A further 12 patients presenting with symptomatic complete heart block remain on treatment with isoprenaline; 3 are men and 9 women. Their ages range from 46 to 82 years, with a mean of 68 years. The dosage ranges from $30-600 \mathrm{mg}$, with a mean of 230 $\mathrm{mg}$ daily. All patients have remained free from Adams-Stokes attacks and heart failure; they feel much better and have a new sense of wellbeing. The average duration of treatment is 2 years I month.

\section{Examples}

An 82-year-old active alderman was seen in March 1968 with a three-month story of ankle oedema and three weeks of frequent AdamsStokes attacks. He was found to be in complete heart block with a ventricular rate of 25 a minute. The intravenous test with isoprenaline increased the ventricular rate to 70 a 
TABLE

\begin{tabular}{|c|c|c|c|c|c|c|c|}
\hline $\begin{array}{l}\text { Case } \\
\text { No. }\end{array}$ & $\begin{array}{l}\text { Age (yr) } \\
(I 963)\end{array}$ & Sex & $\begin{array}{l}\text { Dosage } \\
(m g)\end{array}$ & Before & After & $\begin{array}{l}\text { Duration of } \\
\text { treatment } \\
(y r)\end{array}$ & Comments \\
\hline $\mathbf{I}$ & 32 & $\mathbf{M}$ & 420 & $28-36$ & 56 & $710 / 12$ & Well throughout \\
\hline 2 & 59 & $\mathbf{F}$ & $720-900$ & 32 & 45 & $38 / 12$ & $\begin{array}{l}\text { Well until I } 966 \text { when died } \\
\text { from bronchial carcinoma }\end{array}$ \\
\hline 3 & 67 & $\mathbf{M}$ & 480 & 30 & $34-48$ & $\mathbf{I} / \mathbf{1 2}$ & $\begin{array}{l}\text { Died } 9 \text { days after discharge } \\
\text { from hospital }\end{array}$ \\
\hline 4 & 58 & $M$ & I50 & 33 & 90 & $4 / 12$ & Died from coronary - 1963 \\
\hline 5 & 59 & $\mathbf{M}$ & 480 & 36 & 45 & $79 / 12$ & $\begin{array}{l}\text { Continues very well despite } \\
\text { small rate increase }\end{array}$ \\
\hline 6 & 71 & $\mathbf{F}$ & 180 & 40 & $60-80$ & $77 / 12$ & $\begin{array}{l}\text { Now aged } 79 \text {, recurrent di- } \\
\text { verticulitis but otherwise } \\
\text { well }\end{array}$ \\
\hline 7 & 52 & $\mathrm{~F}$ & 390 & 40 & 65 & $56 / 12$ & $\begin{array}{l}\text { Well; recent readjustment of } \\
\text { treatment }\end{array}$ \\
\hline 8 & 55 & $\mathbf{F}$ & $720-900$ & $15-54$ & 38 & 2 & Died 1965 \\
\hline
\end{tabular}

minute without either side effects or extrasystoles. He has since been treated with isoprenaline $90 \mathrm{mg}$ five times daily and has remained well and fully active without symptoms. The ventricular rate has never been noted to be below 55 a minute. He recently presented with anaemia (haemoglobin 6.8 $\mathrm{g} / 100 \mathrm{ml}$ ) due to a gastrointestinal bleed. In spite of this his cardiac condition remained excellent. A temporary pacing catheter was inserted by the subclavian route to tide him over a gastrectomy for carcinoma of the stomach. Widespread metastases were found. He went back on his usual dose of isoprenaline by mouth and made an uneventful recovery until he died from carcinomatosis and pulmonary emboli some months later.

A 55-year-old woman was seen in March r 963 with a six-week story of frequent AdamsStokes attacks and dyspnoea. She was in 2:I block with a ventricular rate of 44 a minute and from her story it was likely that she had spells of asystole. She was treated with isoprenaline 2 IO $\mathrm{mg}$ a day and went into sinus rhythm with a rate of 100 a minute with occasional dropped beats. When the isoprenaline dose was reduced she reverted to $2: 1$ block. In 1965 the drug was temporarily stopped because of tremor and there was a recurrence of her symptoms. She was restarted on $80 \mathrm{mg}$ three times a day. This cycle of events recurred in 1966 with severe AdamsStokes attacks occurring when the drug was stopped and she was restarted on isoprenaline in six carefully graded doses totalling $450 \mathrm{mg}$ a day. She remained symptom free until 1969 when she again temporarily complained of feeling jumpy and tremulous. In September I970 these symptoms were very troublesome. Her treatment was adjusted by slight reduc- tion in dose and on this she felt well. She remains on $450 \mathrm{mg}$ a day taken in six doses. Her ventricular rate is 52 a minute and she is now aged 59 years.

\section{Saventrine failures}

Thirty-one other patients have been treated for a period with isoprenaline but I I of these died: I from carcinoma of the rectum and the others from cardiac causes. The average age of death was 70 years and the average duration of treatment $\mathrm{I} \cdot 3$ years.

Thirteen have since been paced for the following reasons: continued Adams-Stokes attacks (5), ventricular ectopics (3), side effects of isoprenaline (3), continued heart failure (I), and failure to increase rate (I).

Two of these paced patients have since died. The remaining II are well. The remaining 7 patients form a mixed group: 2 became well without further treatment, 2 left the area and have been lost to follow-up, I reverted to sinus rhythm, I went into atrial fibrillation and felt well, and I had diarrhoea but refused pacing and continues on ephedrine.

\section{Intravenous isoprenaline test}

The test described by Redwood (I968) has proved invaluable in predicting those patients who may not do well on isoprenaline. This test was carried out in 13 of the 31 isoprenaline failure patients. The results indicated that 12 of these would not do well, showing either an increase in ventricular ectopic beats, lack of response to high dosage, extreme sensitivity or unpleasant side effects, particularly feelings of tension. Patients who have subsequently done well on isoprenaline all had good results with this test. One patient who increased her 
ventricular ectopics in the test was considered psychologically unsuitable for pacing and yet has done very well on isoprenaline.

A total of 5 I patients have been treated with isoprenaline for a period of $9 \mathrm{I}$ patient years. Of these patients, 22 have continued satisfactorily for a period totalling $6 \mathrm{I}$ patient years; 23 patients have not done well.

These results show that approximately half the patients who have been treated with isoprenaline have done well. This proportion has been greatly increased since the intravenous isoprenaline infusion test was introduced. The introduction of simpler pacing systems in this region (Clarke, Evans, and

- Milstein, 197I) has extended the scope of long-term pacing but the authors feel that medical treatment still has a small but definite place. The economics of pacing (Whitaker, 1970) make it unlikely that with present methods (Sowton, 1968) all patients who might benefit can be fitted into a reliable

- service and, in some areas at least, drug treatment will continue to have a place in the management of the problem. Our feelings on the selection of cases are in agreement with those stated by Redwood (1969). Attention to the detail of the regimen and the timing, as well as the amount of the dose, is most important in the individual patient.

\section{References}

Bluestone, R., and Harris, A. (1965). Treatment of heart-block with long-acting isoprenaline. Lancet, I, 1299.

Clarke, M., Evans, D. W., and Milstein, B. B. (197I). Long-term pacing with an inductive coupling system. British Heart fournal, 33, 65.

El-Nahas, M. M., and Johnson, A. M. (1966). Clinical evaluation of oral long-acting isoprenaline in treatment of heart-block. British Medical fournal, 2, 735.

Fleming, H. A., and Mirams, J. A. (I963). A clinical trial of a sustained action preparation of isoprenaline in the treatment of heart-block. Lancet, 2, 214.

Redwood, D. (1968). Intravenous isoprenaline and orciprenaline as a guide to the drug treatment of Stokes-Adams attacks. British Medical fournal, $\mathbf{r}$, 419.

Redwood, D. (1969). Conservative treatment of chronic heart block. British Medical fournal, I, 26.

Sowton, E. (1968). Result of a British survey on artificial cardiac pacemakers. British Medical fournal, 2, I I.

Whitaker, W. (1970). Cardiology - World Medicine Review of the Year, February 1970, 51.

Requests for reprints to Dr. H. A. Fleming, Papworth Hospital, Papworth Everard, Cambridgeshire. 